\title{
LOS NUEVOS DERECHOS
}

\author{
MARÍA JOSÉ CORCHETE MARTÍN \\ Profesora Titular de Derecho Constitucional \\ Universidad de Salamanca
}

SUMARIO

I. Rasgos definidores de los derechos fundamentales.

II. Los llamados derechos implícitos. Justificación.

\section{RASGOS DEFINIDORES DE LOS DERECHOS FUNDAMENTALES}

La evolución de los derechos se une de manera estrecha a la evolución del Estado. Resulta ya aceptada, prácticamente con carácter general, la idea de que el nacimiento y desarrollo de los derechos como garantías jurídicas individuales están ligados, inseparablemente, al desarrollo del Estado moderno. Así lo expone con claridad Häberle, para quien la transformación del Estado, es decir, el paso del Estado Liberal al actual Estado social, se plantea en los términos de La Relación Entre Estado Y Derechos Fundamentales ${ }^{1}$. Entre La Doctrina Española, Pérez Luño ${ }^{2}$ habla de nexo de interdependencia, genético y funcional entre el Estado de Derecho y los derechos fundamentales, ya que el Estado de Derecho exige e implica para serlo, garantizar los derechos fundamentales, mientras que éstos exigen e implican para su realización el Estado de Derecho. Es más, el tipo de Estado, liberal o social proclamado en los textos constitucionales, depende del alcance y significado que en ellos se asigne a los derechos fundamentales que, a su vez, ven condicionado su contenido por el tipo de Estado en el que se formulan.

1 P. HÄBERLE, La Libertà fondamentali nello Sato Costituzionale (La nuova Italia Scientifica), ed. di P. Ridola, Roma, Ahulde, 1993, pp. 191-192.

2 A.E. PÉREZ LUÑO, Los derechos Fundamentales, Tecnos, Madrid, 1988, pp. 19-20. 
Esto nos lleva a apuntar que la evolución del Estado, conlleva una evolución en las reivindicaciones sociales, y al revés, como vamos a ver más adelante. Este fenómeno implica, por tanto, y, ya de entrada, que el individuo, de forma progresiva, busca un mejor asentamiento en la sociedad, realizándose de una manera cada vez más plena. Sin duda, las consecuencias jurídicas de esta búsqueda son, hoy en día, claras y evidentes.

La técnica habitual para aproximarse a la problemática de los derechos fundamentales es partir de un modelo tópico, es decir, la aproximación suele circunscribirse a la realidad de un ordenamiento jurídico concreto, limitando de esta forma sus efectos a una realidad espacio temporal determinada. El discurso de este modelo se estructura a partir de las respuestas que se den a estos interrogantes: ¿đónde están esos derechos?, ¿̇uáles son los rasgos identificadores?, ¿qué implican en cuanto a su protección y tutela? El objetivo último es obtener, en la medida de lo posible, lo que Böckenforde denomina, si bien con otro significado, una "teoría de los derechos fundamentales constitucionalmente adecuada".

Desde esta perspectiva, para autores como Cruz Villalón ${ }^{3}$, los derechos fundamentales deben interpretarse como una categoría dogmática del derecho constitucional que nacen con la Constitución, compartiendo con ella su posible eficacia y sus mismos problemas. Pero no sólo esto, en palabras del propio autor, los derechos fundamentales acaban también con las Constituciones. Ello es tanto como afirmar que acaban, hoy por hoy, con los Estados, dentro de los Estados, en el interior del ordenamiento estatal; por lo tanto, los derechos fundamentales son, sencillamente, los derechos en cuanto categorías constitucionalmente relevantes.

$\mathrm{Al}$ margen de otras consideraciones sobre el alcance y calado de estas afirmaciones, incluso de posibles matizaciones, lo que aquí interesa es resaltar, valiéndonos de la expresión que el propio autor toma prestada de Heller, «la conexión de sentido" entre Constitución y derechos fundamentales. A través de esta conexión, que no es más que la expresión de la función integradora que ambos conceptos desarrollan en la actualidad, podremos determinar los rasgos que definen esta categoría en nuestro ordenamiento ${ }^{4}$.

En todo caso, los resultados a que nos lleven nuestras indagaciones en este sentido, se circunscriben a las coordenadas espacio temporales en las que se sitúa nuestro texto constitucional. De ahí que no deba de extrañarnos las diferencias que pueden establecerse con otros ordenamientos de nuestro entorno. Y es que el contenido concreto y la significación de los derechos fundamentales para un Estado dependen de numerosos factores extrajurídicos,

3 P. CRUZ VILLALÓN, "Formación y Evolución de los derechos fundamentales", en La curiosidad del jurista persa y otros estudios sobre la Constitución, CEC, Madrid, 1999, pp. 23 a 54.

4 El origen de esta comprensión de los derechos se suele situar en la Teoría de la integración de SMEND. El Estado como permanente proceso de integración de una comunidad de valores donde los derechos fundamentales serían un elemento más de ese proceso, E.W. BÖCKENFÖRDE, Teoría e interpretación de los derechos fundamentales, Nomos, BADEN-BADEN, 1993, pág. 57. 
especialmente, de la ideosincrasia, de la cultura y de la historia de los pueblos. Por ello, sólo teniendo en cuenta estos aspectos resulta posible una comprensión objetiva de las tareas, la conformación y la eficacia de los derechos fundamentales en un ordenamiento estatal concreto5.

Partiendo de estas premisas, la propuesta es realizar el camino inverso. Ya llegaremos a establecer las notas distintivas, lo importante es conocer cuál ha sido la variación y ampliación del contenido de estos derechos.

\section{BREVE REFERENCIA A LA FORMACIÓN Y EVOLUCiÓN DE LOS DERECHOS FUNDAMENTALES}

La Declaración de los derechos del hombre y del ciudadano de 1789 continúa siendo una referencia obligada para la teoría de los derechos humanos en Europa. Supone el primer documento que recoge por escrito un catálogo de derechos a partir del cual los individuos toman conciencia de su "status" marcando un punto de partida en la lucha social por su "efectividad". Comienza así un proceso de internacionalización de los derechos a nivel universal y regional orientado, con carácter general, hacia la consecución de la dignidad humana en toda su extensión. En expresión de Panebianco, la dignidad humana como background, como uno de los parámetros jurídicos fundamentales para el desarrollo de los diversos ordenamientos ${ }^{6}$.

La experiencia Europea viene marcada por el Convenio Europeo de Derechos Humanos, cuyos efectos positivos son resaltados por la doctrina, fundamentalmente por dos razones. En primer lugar, porque este Convenio ha sido capaz de introducir "standars mínimos", por debajo de los cuales la comunidad internacional estima que no se respetan los derechos humanos ${ }^{7} \mathrm{y}$, en segundo lugar, por su sistema de garantías, «al crear no sólo obligaciones para los Estados sino también derechos accionables por las personas y establecer un mecanismo de tutela propio, no dependiente de cada una de las partes del Tratado" ${ }^{8}$. En este sentido gozaría, como lo ha calificado Saiz Arnáiz, de un carácter sui generis.

El largo período que separa ambos documentos es una prueba de la evolución acontecida en Europa en materia de derechos, lo que nos lleva a

5 K. HESSE, "Significado de los derechos Fundamentales", Manual de Derecho Constitucional, BENDA, MAIHOFER; HESSE y otros, ed. y trad. A. López Pina, Marcial Pons, $2 .^{\text {a }}$ edición, 2001, pp. 83-85.

6 M. PANEBIANCO, "Bundesverfassungsgericht, dignità umana e diritti fondamentalì, Diritto e Società, núm. 2, 2002, p. 151.

7 Vid. L.M. DÍEZ-PICAZO, para quien por esta razón, en el ámbito Europeo ha ido emergiendo una especie de "derecho común" de los derechos humanos que permite alcanzar cierta uniformidad a la hora de resolver los problemas jurídicos que surgen en la práctica, en Sistema de derechos Fundamentales, Thomson-Civitas, 2005, p. 35.

8 A. SAIZ ARNÁIZ, La apertura constitucional al derecho Internacional y europeo de los derechos humanos. El artículo 10.2 de la Constitución española, CGPJ, 1999, p. 136. 
una conclusión evidente, pero no por ello de ser obviada: los derechos humanos no son estáticos sino que evolucionan con la sociedad, con el Estado, con las circunstancias políticas, económicas y sociales.

A partir de aquí y, tomando como hilo conductor de nuestro análisis el carácter dinámico de los derechos, es el momento de recurrir a la acertadísima y sobradamente conocida Teoría generacional de los derechos de Pérez Luño?.

Para no resultar reiterativa y teniendo en cuenta la aceptación generalizada de esta teoría por la doctrina constitucionalista, nos ubicaremos en la tercera generación de derechos. Generación que refleja las circunstancias actuales: una sociedad que, como no podía ser de otra manera, permanece "viva" ante los acontecimientos. Este dinamismo se proyecta sobre los valores $\mathrm{y}$, por ende, sobre los derechos que, de manera inevitable, van actualizando su contenido.

Para Perez Luño esta tercera generación viene a polarizarse en torno a temas tales como el derecho a la paz, los derechos de los consumidores, el derecho a la calidad de vida, o la libertad informática. Se trata, como sostiene dicho autor, de una generación de derechos humanos complementadora de las fases anteriores y se presentan como una respuesta al fenómeno de la denominada "contaminación de las libertades", término con el que algunos sectores de la teoría social anglosajona aluden a la erosión y degradación que aqueja a los derechos fundamentales ante determinados usos de las nuevas tecnologías $^{10}$. No se trata de derechos negativos frente al poder, ni de participación, ni consisten en la obtención de prestaciones públicas, sino que su objeto es proteger bienes comunes, no individuales, que son condición esencial para la "calidad de vida" de cada individuo ${ }^{11}$.

De esta evolución podemos llegar a dos conclusiones principales: por un lado, que el catálogo de derechos no es una obra cerrada pues siempre habrá nuevas necesidades que fundamenten nuevos derechos y, en este sentido, la generación de derechos, será por tanto una generación dinámica, por otro lado, que las funciones que cumplen los derechos fundamentales dentro del ordenamiento jurídico se enriquecen con estas nuevas perspectivas ${ }^{12}$. Ahora bien, tal y como afirma Perez Luño, mientras esos derechos no hayan sido reconocidos en el ordenamiento jurídico nacional y/o internacional, actuarán como categorías reivindicativas, prenormativas y axiológicas. De esta forma,

9 A. E. PÉREZ LUÑO, "Estado Constitucional y Generaciones de derechos", Liber Amicorum Héctor Fix-Zamudio, San José, Costa Rica, 1998.

10 A.E. PÉREZ LUÑO, "Estado Constitucional y Generaciones de derechos humanos", op. cit. p. 1258 .

11 L. LÓPEZ GUERRA, Introducción al Derecho Constitucional, Valencia, 1994, p. 110.

12 En relación con el análisis de las funciones que cumplen los derechos fundamentales dentro de un ordenamiento jurídico, vid J.J. GOMES CANOTILHO, para quien los derechos fundamentales vendrían a cumplir cuatro funciones principales: una función de defensa o libertad, una función de prestación social, una función de protección frente a terceros y una función de no discriminación, en Direito costitucional e Teoria da Costitucao, Coimbra 2000, pp. 383-386 
los derechos humanos evolucionan en dirección al presente acumulando el pasado e integrándolo con cada innovación. En este sentido, la historia de los derechos humanos se revela, a la vez, como paradigma y como progreso constante ${ }^{13}$.

No obstante, esta evolución, aunque pudiera parecerlo, no ha de entenderse como un desplazamiento definitivo de las libertades del individuo a la comunidad. Al contrario, tal y como señala Barile, los nuevos derechos de la segunda y tercera generación suponen un alargamiento del espacio jurídico público pero, también, de la condición individual del hombre y, en todo caso, han de interpretarse como derivaciones directas de los principios que inspiraron en su día la Revolución francesa ${ }^{14}$.

\section{Qué DEFINE A LOS DERECHOS FUNDAMENTALES}

Siguiendo a Hesse, históricamente y, en su significado actual, los derechos fundamentales son, sobre todo, derechos humanos: lo que con ellos se pone en juego son las condiciones esenciales de la vida individual y comunitaria en la libertad y dignidad humana, una tarea que no ha perdido, en las circunstancias presentes, su importancia para nuestro tiempo ${ }^{15}$. En este sentido y, conectando con la definición de derechos humanos formulada por Perez Luño, constituirían "un conjunto de facultades e instituciones que, en cada momento histórico, concretan las exigencias de la dignidad, la libertad y la igualdad humana, los cuales deben ser reconocidos positivamente por los ordenamientos jurídicos a nivel nacional o internacional ${ }^{16}$. El Tribunal Constitucional a lo largo de su jurisprudencia ha ido formulando y completando el concepto de derechos fundamentales pero siempre resaltando la doble vertiente de los mismos, como derechos subjetivos y como «...elementos esenciales del ordenamiento jurídico objetivo de la comunidad nacional..., ${ }^{17}$.

Para Peces Barba ${ }^{18}$ la expresión derechos fundamentales abarca, frente a otras expresiones como derechos humanos, todas las dimensiones, sin incurrir

13 A.E. PÉREZ LUÑO, "Estado Constitucional y Generaciones de derechos”, op. cit. p. 1258.

14 P. BARILE, "Nuovi diritti e libertà fondamentali", en Nuovi diritti dell"età tecnologica, Milano, 1991.

15 K. HESSE, "Significado de los derechos fundamentales", Manual de Derecho Constitucional, Benda, Maihofer, Vogel, Hesse y Heyde, ed. y trad. A. LOPEZ PINA, IVAP, Marcial Pons, Madrid, 2000, p. 115.

16 A.E. PÉREZ LUÑO, Los derechos Fundamentales, op. cit. p. 44.

17 Ya en la primera sentencia del Tribunal Constitucional español se admitía expresamente el carácter principalmente subjetivo, pero accesoriamente objetivo de los derechos fundamentales. Esta doctrina ha sido mantenida por el Tribunal Constitucional cuando, de manera reiterada, hace alusión a la "doble dimensión" de los derechos fundamentales. Vid, entre otras, las SSTC 1/1981, 25/1981, 53/1985, 64/1988, 129/1989, etc.

18 G. PECES-BARBA, Curso de derechos Fundamentales, Teoría General, Univ. Carlos III, BOE, Madrid, 1999, pp. 36 y ss. 
en reducciones iusnaturalistas o positivistas; expresan tanto una moralidad básica como una juridicidad básica. Así, frente a otras denominaciones, el concepto de derecho fundamental da cuño a un nuevo concepto de Estado, el Estado constitucional de Derecho, y al igual que este supone una síntesis de las distintas etapas fenomenológicas de la estructura estatal (Estado liberal, democrático y social), el concepto de derechos fundamentales vendría a ser una expresión sincrética que en principio serviría para dar cabida a los derechos nacidos para la satisfacción de las distintas etapas históricas y, en todo caso, no tanto de la superación de la vieja polémica en cuanto a su fundamentación, entre positivistas e iusnaturalistas, pero sí en su atemperación.

Solozabal ${ }^{19}$, también centra el concepto de derechos fundamentales desde una perspectiva material. Para este autor, los derechos fundamentales reconocen facultades referentes a ámbitos vitales del individuo en su propia libertad, relaciones sociales o participación política, imprescindibles para su desarrollo como persona y derivados de su propia dignidad como tal. Para este autor, desde el punto de vista individual, los derechos fundamentales están ligados a la dignidad de la persona, son la proyección positiva, inmediata y vital de la misma. Constituyen la condición de su libertad y autodeterminación. Su conculcación vulnera la dignidad e impide el desarrollo del individuo como persona. Por eso, los derechos fundamentales constituyen el núcleo básico, ineludible e irrenunciable, del status jurídico del individuo. Pero, también, tienen una dimensión objetiva. Son condición misma de la democracia y, además, normas competenciales del ordenamiento jurídico, en la doble medida en que establecen espacios protegidos de la intervención estatal que ésta ha de respetar y, asimismo, en el sentido en que, incluso cuando una acción normadora sea imprescindible, la misma no puede realizarse por cualquier sujeto público, sino sólo por el legislador.

Pero el elemento en verdad relevante que distingue a estos derechos y los dota de su especial naturaleza jurídica, reside en la positivación constitucional. De ello derivan, en el plano jurídico, la supralegalidad y la rigidez, así como su doble dimensión normativa, como derechos subjetivos y como valores y principios constitucionales que se traducen en mandatos de actuación para todos los poderes constituidos. Es en estos elementos donde se encuentran las bases del régimen jurídico de los derechos fundamentales. También, de la consagración constitucional deriva buena parte de su significado político, como fuente de legitimidad, pautas de comportamiento que articulan la convivencia ciudadana y utopías de libertad. En definitiva, en el rango constitucional se encuentra la nota común de estos derechos, que permite darles un tratamiento categórico de unidad.

19 J. J. SOLOZÁBAL ECHEVARRÍA, "Algunas cuestiones básicas de la teoría de los derechos fundamentales", REP, núm. 71, enero-marzo, 1991, pp. 87-89.

El Tribunal Constitucional ya se pronunció sobre el doble carácter de los derechos fundamentales en la sentencia 25/1981: como derechos subjetivos, en cuanto garantizan un status jurídico o la libertad en un ámbito de existencia, como derechos objetivos, constituyen elementos esenciales de un orden objetivo de la comunidad nacional. 
Por tanto, y partiendo de la ya mencionada "conexión de sentido" entre Constitución y derechos fundamentales, debemos tomar como punto de partida el ordenamiento español si queremos aproximarnos a la definición de los derechos fundamentales, como acertadamente apunta Martin Retortillo ${ }^{20}$, por más prestigio que tengan determinadas declaraciones, por fuerte que sea el impulso internacionalizador, el punto de partida inexcusable es la realidad propia y original del Derecho español.

Sin embargo, a pesar de acotar el campo material a un ordenamiento determinado, la tarea no resulta sencilla. En nuestro ordenamiento, ya desde un primer momento, se detectó un problema de identidad en torno a esta categoría dogmática.

Para Cruz Villalon ${ }^{21}$ este problema se plantea, básicamente, por la gran desigualdad de las garantías que protegen, respectivamente, a los derechos comprendidos en las dos secciones en que se divide el capítulo segundo del título I de la Constitución: distinta rigidez constitucional, distinta tutela judicial y, además, distinta reserva legal con arreglo a la interpretación efectuada del artículo 81.1 CE.

Todo ello ha provocado que este término se haya utilizado, por el Tribunal Constitucional, en un sentido anfibológico. Esto es, por un lado se ha utilizado el término "derechos fundamentales" en sentido amplio y, por tanto, en términos equivalentes a los que se dan en el Derecho Comparado pero, por otro lado, tiende a utilizarse con un significado restrictivo cuando se trata de la delimitación de la reserva de ley orgánica.

Intentando poner fin a esta situación y, conscientes de que estamos ante una categoría básica del Derecho Constitucional contemporáneo, Cruz Villalon trata de establecer una serie de proposiciones generales para acercarse a este objetivo. Así, para este autor, tan importante es la vertiente material como formal de los derechos y, en este sentido, cabría hablar, no sólo de un "Contenido esencial" de cada uno de los derechos fundamentales, sino también, de un contenido esencial de los derechos fundamentales en su conjunto, como categoría. Este contenido esencial estaría integrado por una vertiente material y una vertiente formal.

En su vertiente material, ya hemos visto algunas definiciones que vinculan estos derechos a la idea de libertad y dignidad humana. Sería el concepto con el que vendría operando nuestro Tribunal Constitucional, el Tribunal Europeo de Derechos Humanos y el Tribunal de Justicia de las Comunidades Europeas. De este modo, el Derecho Constitucional Comparado tendería a operar, en este ámbito, como "el Derecho Natural de hoy en día".

En su vertiente formal, el contenido esencial de los derechos fundamentales se integraría por un elemento genérico, común a todo derecho, la ga-

20 L. MARTÍN RETORTILLO-I. DE OTTO y PARDO, Derechos Fundamentales y Constitución, Madrid, 1988, pp. 23-24.

21 P. CRUZ VILLALÓN, "Derechos Fundamentales y Legislación", en La curiosidad del jurista persa, y otros estudios sobre la Constitución, CEP y C, Madrid, 1999, pp. 234-237. 
rantía judicial, y un elemento específico de todo derecho fundamental: la vinculación del legislador. Por tanto es la capacidad de vincular al legislador lo que hace de un derecho, un derecho fundamental.

Las consecuencias de estas afirmaciones sobre el ordenamiento español serían claras: en su vertiente material, los derechos fundamentales no se agotarían en la sección primera del capítulo segundo del título I CE, operando así, en el marco del Derecho Constitucional Comparado donde el punto de referencia sería el Convenio Europeo de Derechos Humanos. En cuanto a su vertiente formal, los derechos fundamentales se identificarían con el capítulo segundo del título I CE, ya que es aquí donde se contiene la característica específica de los derechos fundamentales, esto es, la vinculación del legislador.

En cuanto a la tutela judicial extraordinaria del artículo 53.2 y la reserva de Ley orgánica, se trataría, para este autor y para la mayoría de la doctrina, puesto que se trata ya de una cuestión pacífica, de garantías con una relevancia meramente cuantitativa, que quedarían reservadas para los derechos de la sección primera.

Respecto a los derechos del capítulo tercero, las opiniones doctrinales caminan en una misma dirección. Para Cruz Villalon en principio, no serían calificados como derechos fundamentales conforme al contenido del artículo 53.3 CE, salvo que sean dotados de tutela judicial y, sobre todo y principalmente, en la medida en que el legislador pueda verse efectivamente limitado por estos derechos. Entonces, se produciría una "fundamentalización" de los mismos. Sin embargo, quien realmente transforma estos principios en derechos no es el constituyente, sino el legislador.

En parecidos términos se expresa Jimenez Campo ${ }^{22}$ para quien lo propio de los derechos fundamentales es su creación por la Constitución. Significa que la propia Constitución ha definido una determinada situación jurídica en términos que la hacen identificable para el intérprete y que, además, ha determinado, también, la necesaria consideración de esa situación jurídica como "derecho" a partir de la entrada en vigor de la norma que lo enuncia. Para este autor, la primera operación constituyente se refleja en cada una de las normas que califican o describen como "derechos" bienes jurídicos y, la segunda operación la lleva a cabo en los apartados 1 y 3 del artículo 53: en el primero al afirmar la preexistencia del derecho fundamental respecto a toda intervención legislativa y la vinculación a su contenido por parte de todos los poderes públicos; en el tercero, para excluir tal vinculación directa a los que la Constitución llama "principios rectores de la política social y económica". Es decir, la distinción verdaderamente relevante entre unos y otros es que en tanto los derechos del capítulo segundo, es decir los derechos fundamentales, existen antes y sin perjuicio de su regulación legislativa, los principios del capítulo tercero sólo serán "derechos" a partir "de las leyes que los desarrollen" y conforme a lo dispuesto en ellas.

22 J. JIMÉNEZ CAMPO, Derechos Fundamentales. Concepto y Garantías, Trotta, Madrid, 1999, pp. 24-25. 
De esta inescindibilidad entre Constitución y derechos fundamentales se desprende además, entre otras consecuencias, la proyección de los caracteres propios de la Norma Fundamental sobre cada uno de sus contenidos y, así, de cómo entendamos la Constitución dependerá la concepción de los derechos fundamentales ${ }^{23}$.

El concepto de constitución constitucionalmente adecuado, se muestra idóneo para identificar nuestra Norma fundamental y, con ello, las Constituciones de aquellos países que conforman nuestro entorno. En este sentido, la Constitución de 1978 responde a un concepto de Constitución abierto y pluralista $^{24}$. Pues bien, estos caracteres los encontramos, igualmente, en determinados preceptos constitucionales, y de manera especialmente clara, en aquellos relativos a derechos fundamentales.

Los enunciados de este tipo de derechos están consagrados mediante fórmulas semánticas abiertas, que suelen caracterizarse por su escasa densidad regulativa y por su carácter abierto e indeterminado. En este sentido, participan del carácter fragmentario y abstracto que acompaña a la Constitución en la que se inscriben ${ }^{25}$. De ahí que sea indispensable la intervención legal, pero sólo para que estos derechos alcancen una virtualidad y eficacia plenas. Así, la aplicación de estos derechos por los jueces impone una interpretación que integra tanto los desarrollos legislativos e institucionales de los derechos en cuestión, como las circunstancias fácticas de los casos sometidos a su resolución. De igual modo, la positivación constitucional de estos derechos combina el catálogo casuístico con cláusulas generales de validez que pasan a formar parte de aquellos, y a partir de las cuales es posible, también, elaborar reglas particulares sobre derechos fundamentales. Los enunciados sobre fines del Estado, primacía de los derechos humanos, o la proclamación de la libertad, la igualdad y la dignidad como fundamento del orden jurídico, integran igualmente, la consagración normativa de los derechos fundamentales ${ }^{26}$.

23 Ya en la primera sentencia del Tribunal Constitucional español se admitía expresamente el carácter principalmente subjetivo, pero accesoriamente objetivo de los derechos fundamentales. Esta doctrina ha sido mantenida por el Tribunal Constitucional cuando, de manera reiterada, hace alusión a la "doble dimensión" de los derechos fundamentales. Vid, entre otras, las SSTC 1/1981, 25/1981, 53/1985, 64/1988, 129/1989, etc.

24 Constitución pluralista en el sentido expresado por ZAGREBELSKY, como "un compromiso de posibilidades", donde la ley expresa las combinaciones posibles entre los principios constitucionales que se limitan a establecer los puntos irrenunciables de cualquier combinación. Será un Derecho que refleja el punto de vista de los sujetos políticos que, ocasional y temporalmente, logran prevalecer en el proceso legislativo en virtud del principio de mayoría. En $E l D e-$ recho Dúctil, Trotta, 1995, p. 97.

25 Autores como H.P. SCHNEIDER y J.J. G. CANOTILHO, entre otros, hacen referencia no sólo al carácter abierto de la Constitución sino, también, al carácter abierto de las propias normas constitucionales. La consecuencia inmediata de todo ello no es otra que flexibilizar el contenido de los preceptos constitucionales ante la realidad cambiante. En Democracia y Constitución, CEC, pp. 49-50, y Direito Constitucional, Almedina, Coimbra, 2000, p. 188, respectivamente.

26 Es el caso de la dignidad, entre otros ejemplos citados. Para ROLLA puede ser utilizada como criterio de interpretación de los derechos previstos en las Cartas constitucionales, en el sentido que llevan a enuclear entre las múltiples disposiciones constitucionales en materia de dere- 
En todo caso conviene insistir en que dado el carácter abierto y pluralista de las Constituciones modernas, no cabe calificar a los derechos como límites absolutos e infranqueables para la acción del Estado. Es decir, los poderes públicos ven constreñida su actividad por estos contenidos pero, en los términos marcados por la Constitución. Teniendo en cuenta esa apertura constitucional y ese carácter plural, también los derechos fundamentales se ven contagiados de estos caracteres. Por eso, los derechos fundamentales también deben adaptarse al momento y al lugar en que deben aplicarse.

\section{LOS LLAMADOS DERECHOS IMPLÍCITOS. JUSTITFICACIÓN}

La experiencia nos demuestra que nos encontramos en un momento histórico donde resulta, prácticamente evidente, negar el reduccionismo liberal, al igual que el concepto racional normativo de Constitución, entendido como proyecto de organización establecido de una sola vez y para siempre, donde tienen cabida, directa o indirectamente, todos los problemas. Frente a éste, mantenemos un concepto de Constitución abierta, puesto que no se puede entender que las declaraciones deban tener pocos derechos como las declaraciones liberales, y que se considere un catálogo cerrado y excluyente, concepto que, por otro lado, era una lógica consecuencia de la concepción iusnaturalista de los derechos de la que se desprendía un conjunto de valores ahistóricos y con vocación de universalidad e inmutabilidad.

Lo que se está produciendo, en realidad, es el paso del hombre abstracto al hombre concreto y esto, para Bobbio implica una ampliación del ámbito de los derechos del hombre, a través de un proceso de gradual diferenciación o especificación de las necesidades y de los intereses, de los que se exige su reconocimiento y protección. Los derechos no nacen todos en un momento. Nacen cuando deben o pueden nacer ${ }^{27}$.

Con carácter general, los ordenamientos constitucionales colocan en el centro del sistema de protección de los derechos fundamentales a la persona humana entendida, no como individuo aislado, sino en su proyección social. Además, el carácter abierto de los textos constitucionales actuales conlleva que el catálogo de derechos destinado a la promoción de la persona humana, dentro de su comunidad, no sea estático. Constantemente, y más en los últi-

chos, particulares perfiles de la personalidad humana que concurren a delinear el derecho de toda persona a la dignidad y al desarrollo de la propia personalidad. En este sentido, podría ser considerado un principio rector según el cual una disposición susceptible de asumir diversos significados, debe interpretarse en el sentido más conforme con el principio de dignidad, o bien, no puede ser legítimamente adoptada una interpretación contraria o en conflicto con tal valor. Vid G. ROLLA, "Técnicas de garantía y cláusulas de interpretación de los derechos fundamentales. Consideraciones sobre las Constituciones de América Latina y de la Unión Europea", Revista Europea de Derechos Fundamentales, núm. 7, primer semestre 2006, p. 58.

27 N. BOBBIO, El Tiempo de los derechos, sistema, 1991, pp. 15-18. 
mos tiempos, con los avances de la ciencia y las nuevas tecnologías, se percibe una imperiosa necesidad de actualizar los derechos fundamentales; esto es, conectarlos con las nuevas exigencias de la persona humana. A ello se refiere Häberle ${ }^{28}$ cuando hace alusión a la fuerza expansiva de los derechos fundamentales. El autor alemán subraya que esa fuerza expansiva se despliega en el transcurso del tiempo y, así, podemos observar que los derechos fundamentales cuentan con una dinámica propia que les permite desdoblarse hacia nuevos espacios y ensanchar su contenido. Es, por tanto, evidente, que existe una relación directa entre el desarrollo de los derechos fundamentales y los procesos culturales, que no hace sino confirmar empíricamente la teoría Häberliana. El argumento de que el tiempo contribuye a consolidar la eficacia de los derechos fundamentales también queda corroborado en la práctica, e indica hasta qué punto se armonizan estos derechos con los ámbitos culturalmente más avanzados. Lo más importante es que ambos procesos, el normativo y el cultural, se estimulan recíprocamente. Ahora bien, lo contrario también puede ocurrir: en la medida en que se deteriora el entorno cultural, o las funciones normativas se ven entorpecidas, se advierte un retroceso de derechos fundamentales.

En este sentido y, como acertadamente ha apuntado SPADARO, no se puede ignorar, a la luz de las mutaciones, el actual y delicado paso de época que inevitablemente hace "crujir" las pluridecenales estructuras jurídicas vigentes, también constitucionales, y parece que propiamente a los juristas les toca señalar, con simplicidad y claridad, los límites de adaptabilidad de las estructuras normativas existentes a la evolución en curso $^{29}$.

Pues bien, el concepto de derechos implícitos ha sido tratado, en profundidad y, desde hace años, por la doctrina italiana, precisamente, para dar cabida a lo que, en sentido amplio, se denominan "nuevos derechos", y que responde a este proceso de adaptación del Derecho a la evolución de los tiempos.

Como ya apuntara Baldassarre, los derechos implícitos son directa consecuencia del mutado concepto de "persona humana" presente en los modernos Estados democráticos. Así, estos derechos quedarían comprendidos en el contenido semántico de derechos más amplios, expresamente recogidos en la Constitución. Además, también serían derechos "instrumentales" en el sentido de que la falta de éstos para los derechos enumerados, supondría vaciarlos de significado o, no garantizarlos de una manera suficiente. Este tipo de derechos puede aparecer aisladamente o, en combinación con otros, pero siempre sobre la base de las normas relativas a los derechos enumerados constitucionalmente ${ }^{30}$.

28 P. HÄBERLE, El Estado Constitucional, UNAM, México, 2001, p. LXI. p. 467.

29 A. SPADARO, «Il problema del fondamento dei diritti fondamentali», Diritto e Società, 1991,

30 A. BALDASSARRE, "Diritti inviolabili", Diritti della persona e valori costituzionali, Torino, 1997, pp. 59-60. 
Modugno $^{31}$ se muestra partidario de "hipotizar" sobre nuevos derechos emergentes de la conciencia social, independientemente de su reconocimiento normativo, sin implicar, por ello, una alteración del catálogo constitucional. Sin embargo, partiendo de la Constitución italiana, esto no es posible. Sí en cambio, lo que él denomina como «explicitación de los derechos implícitos", como posibles consecuencias de los derechos enumerados constitucionalmente. En la misma línea que Baldassarre, para este autor, estos derechos pueden ser construidos como derechos instrumentales, aunque también es posible, combinando entre ellos más normas constitucionales, configurar derechos "transversales" ya que, partiendo de la evolución de significado de las disposiciones constitucionales, es posible hallar en éste, el fundamento positivo de derechos, por ahora, no contemplados en cuanto no reconocibles.

Por eso, en realidad y, en sentido estricto, los derechos implícitos, no son nuevos derechos. Revenga Sanchez ${ }^{32}$ destaca que el factor novedad se constata a la luz del contraste entre el texto que se escribe como resultado de un "momento constitucional" y el despliegue efectivo de dicho texto, situado en el tiempo, y "desbordado" precisamente allí donde se trataba de delimitar el espacio general de libertad garantizado a sus destinatarios. Sin escritura constitucional que actúe de espejo, para este autor, no puede haber, por definición, derechos calificados de nuevos.

Esta es la línea general de pensamiento de la que debemos partir. Sin embargo algunos autores, entre ellos Pace, se pregunta si debemos hablar de derechos fundamentales como una categoría que incluya sólo algunos derechos constitucionalmente reconocidos, o bien, incluyendo, además, derechos no expresamente previstos en la Constitución. Para el autor italiano, esto es peligroso porque legitima una fuga a favor de opciones interpretativas individuales; una fuga que presupone un infundado optimismo sobre cómo los valores constitucionales - de los cuales cada vez se postula, sin más, un superávit normativo respecto a las mismas disposiciones constitucionales-, serán concretamente traducidos por el intérprete en concreta situaciones objetivas (favorables y desfavorables). Este problema y algunos más que analizaremos a continuación, ponen de manifiesto, no la existencia de dificultades en torno al concepto mismo de derechos implícitos, sobre el cual, como hemos visto, existe, prácticamente, un pleno acuerdo, sino, sobre todo, en sus vías de reconocimiento constitucional y, por ende, en sus consecuencias jurídicas. Vamos, entonces a examinarlas, más detenidamente.

31 F. MODUGNO, I nuovi diritti nella Giurisprudenzia Costituzionale, Torino, 1995, pp. 1-2.

32 M. REVENGA SÁNCHEZ, "Sobre (viejos) modelos de justicia constitucional y creación de (nuevos) derechos", REDC, año 22, núm. 64, enero-abril 2002, pp. 99-100. 


\section{PRinCipales VÍAS DE RECONOCIMIENTO CONSTITUCIONAL DE LOS DERECHOS IMPLÍ́CITOS*}

Para Häberle ${ }^{33}$, el espacio y el tiempo constituyen dos factores a tener muy en cuenta por el Derecho Constitucional. Ambos factores trabajan en el tipo de Estado Constitucional. Ello lleva a que la metodología constitucional se haga correlativamente extensa. Pero sólo así, el Estado Constitucional asegura su continuidad y supervivencia en el curso del tiempo a través de procedimientos e instrumentos de distinto espesor, en la búsqueda de un equilibrio entre constancia y cambio. Dentro de los instrumentos y procedimientos — en terminología de Häberle- para el procesamiento del factor tiempo en el presente y en el futuro, la doctrina ha señalado diversos caminos de integración, en el ordenamiento jurídico, de esta categoría de derechos que hunden sus raíces en la Constitución sin ser expresamente fijados en ella. Vamos a examinar las vías que, a nuestro parecer, han sido en mayor medida analizadas por la doctrina y que, en cualquier caso, constituirían vías aceptadas por la mayoría de ella aunque siempre, con ciertos matices.

\section{A) Las cláusulas Generales de validez}

En algunos textos constitucionales europeos aparecen este tipo de Cláusulas que permiten una interpretación evolutiva de los derechos fundamentales. Concretamente, representan una base razonable para que la jurisprudencia pueda provocar, en términos jurídicos, "una evolución" en los derechos.

Rolla ${ }^{34}$ hace referencia a estas cláusulas, con carácter general, y establece que, a través de ellas se puede asegurar una continua síntesis entre disposiciones constitucionales y valores contemporáneos, entre Derecho e historia; pero, al mismo tiempo, consienten orientar la disputa relativa a la posibilidad de introducir los "nuevos derechos" entre los derechos fundamentales de la persona.

Sin embargo, resulta necesaria una operación previa, la de distinguir, como así lo hace este autor, entre los derechos que son "nuevos" en cuanto no expresamente regulados en el catálogo constitucional, aunque pueden ser

* En este epígrafe nos centraremos en el análisis de las principales vías de reconocimiento constitucional de los derechos implícitos, siendo conscientes de la existencia de otros instrumentos que podrían resultar idóneos para cumplir con dicho cometido aunque no sean objeto de este trabajo. Sería el caso del voto particular, instrumento que "tiende" a colaborar en el desarrollo del Derecho y, en relación con la jurisprudencia constitucional, en el desarrollo de los contenidos constitucionales, favoreciendo la formación de una jurisprudencia evolutiva. Sirvan como lecturas orientativas en relación con esta función, F. J. EZQUIAGA GANUZAS, El voto particular, CEC 1990, J. L. CASCAJO CASTRO, "La figura del voto particular en la jurisdicción constitucional española", REDC, núm. 17, 1986.

33 P. HÄBERLE, El Estado Constitucional, op. cit., pp. 60 y ss.

34 G. ROLLA, "Le prospettive dei diritti della persona alla luce delle recenti tendenze costituzionali", Quaderni Costituzionali, a. XVII, núm. 3, dic. 1997, pp. 458-459. 
extraídos de las disposiciones relativas a los derechos fundamentales a través de las referencias al principio personalístico remitido por las cláusulas generales, y aquellos derechos que, en cambio, son nuevos en cuanto no comprendidos ni tampoco deducibles de dicho catálogo constitucional.

Para el autor italiano, de tal criterio deriva una doble consecuencia: sólo los primeros pueden ser incluidos, con pleno título, entre los derechos fundamentales, gozando así de la misma protección de los derechos a los cuales se reconducen. Los segundos, no poseen una cobertura constitucional, sino legislativa y, por tanto, su tutela dependerá del legislador. Forman parte, no de la Constitución, sí de la materia constitucional.

Además, éstos últimos serían calificables, en rigor, de nuevos derechos, mientras que los primeros son sólo formalmente nuevos, puesto que su presencia es inmanente a las fórmulas constitucionales que disciplinan uno o más derechos fundamentales. De esta forma, su posterior concreción por el legislador o por la jurisprudencia, no tendrá naturaleza creativa en sentido propio, sino meramente verificativa: el intérprete explicita la función de derechos conexos a los valores que ya han sido positivamente codificados. En estos casos, el "supuesto nuevo derecho" no puede considerarse separado del viejo; las nuevas posiciones subjetivas — gracias a la intermediación de la cláusula general- hunden sus raíces en el fértil terreno del catálogo constitucional.

Las Cláusulas generales suelen preceder a las codificaciones de concretos derechos, y pueden ser reconducidas a dos categorías distintas, pero funcionalmente coordinadas. Según que consientan una ampliación y una implementación de las posiciones jurídicas tuteladas a través del reclamo a la normativa internacional, por ejemplo el artículo 10.2 de la Constitución española; o bien, que consigan tal resultado de una interpretación evolutiva y constructiva de los derechos fundamentales relativos a la persona, por ejemplo el artículo 2 de la Constitución Italiana ${ }^{35}$, y el artículo 2 de la Ley Fundamental alemana $^{36}$, y nosotros añadiríamos, el artículo 10.1 de la Constitución española ${ }^{37}$.

Este "último" precepto reviste, según las distintas posiciones doctrinales al respecto, un doble valor. Para un sector de la doctrina, el valor del artículo 10.1 de nuestra Constitución es esencialmente hermenéutico y, por tanto, puede utilizarse a los efectos de interpretar los diversos preceptos constitucionales, pero no tendría un carácter autónomo ${ }^{38}$. De otro lado, nos encontramos

35 El artículo 2 de la Constitución italiana establece "La República reconoce y garantiza los derechos inviolables del hombre, ya sea como individuo ya sea en las formaciones sociales donde desarrolla su personalidad, y exige el cumplimiento de los deberes inderogables de solidaridad política, económica y socialn.

$36 \mathrm{El}$ artículo 2 de la Ley Fundamental alemana establece que todos tienen derecho al libre desarrollo de la personalidad.

37 Sobre las funciones del art 10.1 CE, vid J. RUIZ-GIMÉNEZ CORTES, «El artículo 10. Derechos Fundamentales de la Persona", Comentarios a la Constitución Española de 1978, dir. O. Alzaga Villaamil, Tomo II, Cortes Generales, Edersa, 1997, pp. 58-59.

38 Entre los que participan de esta idea podemos citar a F. RUBIO LLORENTE, Prólogo a la obra, Derechos fundamentales y Principios constitucionales, dir. Por el mismo autor, Barcelona, Ariel, 1995, pp. XII-XIII; M. ARAGÓN, Constitución y Democracia, Madrid, Tecnos, 1989, pp. 67-113. 
con autores, como Tomas Y Valiente ${ }^{39}$ quien defendía que los valores superiores - artículo 1.1-y, por tanto, también podríamos extenderlo a los recogidos en el artículo 10.1, contribuyen a dotar a la Constitución de "resistencia", en el sentido de capacitarla para adaptarse al cambio sin ceder en su propia identidad, y sin necesidad de proceder a su reforma. Basile va más allá y, así, para este autor italiano, de la cláusula de dignidad que se recoge en el artículo 10.1 de la Constitución española "...se deduce con gran facilidad un principio de favor libertatis que el intérprete de la Constitución deberá tener siempre presente". Y añade: "no se excluye que, sobre esta base, los jueces españoles no sólo podrán entender con carácter extensivo lo que está explícitamente garantizado en el Título I, sino que podrán llegar a considerar implícitos en él incluso otros derechos que no se garantizan expresamente, ${ }^{40}$.

En cuanto al artículo 2 de la Constitución italiana, la Corte Constitucional ha interpretado sustancialmente la expresión "derechos inviolables" como formulación directa a reconocer un determinado estatuto jurídico a derechos explícita o implícitamente reconocidos en otras normas constitucionales. La orientación, ya suficientemente consolidada por la jurisprudencia constitucional italiana, es la de utilizar el artículo 2 como base cualificadora respecto a los derechos explícita o implícitamente reconducibles a otras normas constitucionales. Con ello, la Corte rechaza, en general, la consideración de este precepto como fuente autónoma de derechos o, dicho de otro modo, ha excluido que pueda ser considerado como medio técnico de reenvío a derechos ulteriores del todo desvinculados a los derechos enumerados constitucionalmente ${ }^{41}$.

Si como hace Ferreres Comella comparamos el modelo europeo, que sigue unos planteamientos similares en cuanto a la evolución de los derechos desde la propia Constitución formal, con el contexto americano, podemos comprobar

39 F. TOMÁS y VALIENTE, "La resistencia constitucional y los valores”, DOXA 15-16, 1994, p. 642. Entre los que defienden esta postura, A. GARRORENA, "Valores superiores y principios constitucionales", en Estudios de Derecho Público en bomenaje a J.J. Ruiz Rico, Madrid, Tecnos, 1997, pp. 36-37; G. PECES BARBA, Los Valores superiores, Madrid, Tecnos, 1984; A.E. PÉREZ LUÑO, Los derechos fundamentales, Madrid, Tecnos, 1995; L. PRIETO SANCHIS, Estudios sobre derechos fundamentales, Madrid, Debate, 1990, entre otros.

40 S. BASILE, "Los valores superiores, los Principios fundamentales y los derechos y libertades públicas", en A. Predieri y E. García De Enterría, La Constitución española de 1978. Estudio sistemático, Madrid, civitas, 1981, p. 274.

Además sobre la defensa de este planteamiento, vid el voto particular de Jiménez de Parga a la STC 290/2000 — al que se adhiere Mendizábal Allende- y en donde este magistrado defiende el carácter principal del artículo 10.1 CE en la verificación del derecho fundamental a la protección de datos.

41 Cfr A. BALDASSARRE, "Diritti inviolabili", Diritti della persona e valori costituzionali, Torino, 1997, especialmente págsp 59-61. Sobre el artículo 2 de la Constitución italiana existe una implísima referencia bibliográfica, sirva a título ejemplificativo: F. MODUGNO, "La tutela dei nuovi diritti", Nuovi diritti dell' etá tecnologica, a cura di F. Riccobono, y del mismo autor, I nuovi diritti nella Giurisprudenza Costituzionale Torino, 1995; A. SCALISI, Il valore della persona nel sistema e I nuovi diritti della personalità, Milano, 1990; A. SPADARO, "Il problema de fondamento dei diritti Fondamentali", Diritto e Società, 1991; A. PACE, "Diritti fondamentali al di là della Costituzione», Politica del Diritto, a. XXIV, núm. 1, marzo de 1993, entre otros. 
cómo el argumento de fondo es el mismo. «La Constitución de EEUU, con más de doscientos años, ha podido adaptarse a las nuevas necesidades, sobre todo, en materia de libertades, no sólo porque ha sido enmendada en varias ocasiones, sino también porque algunas de las disposiciones del texto original y de sus enmiendas son de carácter abstracto ${ }^{42}$. En este sentido, cabe destacar la decimocuarta enmienda del "proceso debido", utilizada por la jurisprudencia como norma protectora de los derechos fundamentales de libertad no recogidos de manera explícita en la Constitución y que ha servido de base para elaborar una magnífica jurisprudencia sobre la dignidad humana así como un procedimiento para exigirla ${ }^{43}$. Entre los derechos reconocidos de esta forma cabe citar desde el derecho al voto, a la libertad de circulación, libertad de asociación, es decir, derechos fundamentales recogidos expresamente en todas las Constituciones de Estados democráticos.

En definitiva y, tomando como fundamento la praxis constitucional propia y comparada, podemos concluir diciendo que, a nuestro parecer, sin la existencia de estas cláusulas resulta difícil una posible ampliación de los derechos específicamente recogidos en la Constitución, si no es a través de una reforma del texto. El hecho de que estos valores y derechos expresamente recogidos en los textos constitucionales sean formulados de manera abstracta permiten esta evolución. Bien es verdad que el texto de la Constitución española resulta un texto relativamente reciente pero es un hecho que la sociedad no es inmutable y sus "nuevos problemas" no previstos expresamente por el constituyente, necesitan una respuesta que, obviamente, tendrá, también, un carácter variable. Precisamente Schneider apunta como característica de las Constituciones modernas su incompletud. Determinados ámbitos de la vida que quedan sin regular, o sólo parcialmente, o importantes cuestiones que se dejan conscientemente abiertas en manos de la libre confrontación política, e incluso el autor alemán va más allá resaltando el carácter abierto de las propias normas constitucionales, ya antes mencionado. Estas, debido a su alto grado de abstracción, necesitan de una concreción escalonada. Según esta variedad de significados, la Constitución se muestra abierta "hacia arriba" al Derecho Natural, los derechos humanos, los principios jurídicos generales, el Derecho Internacional Público, la integración supranacional, y "hacia abajo” es variable al interpretar los conceptos básicos generales como la libertad, la igualdad, el bienestar, y los derechos fundamentales ${ }^{44}$. En la misma línea se expresa Baldassarre ${ }^{45}$ quien insiste en que la lógica y la teoría de los valores sean las más apropiadas para comprender las constituciones democráticas modernas que, a diferencia de las liberales (concentradas en los límites al poder público) son esencialmente de valores. En este sentido, representan el fun-

42 V. FERRERES COMELLA, Justicia Constitucional y Democracia, CEPyC, Madrid. 1997, p. 117. 43 Veáse al respecto, B. NEUBORNE, El papel de los juristas y del imperio de la Ley en la sociedad americana, Madrid, civitas, 1995, pp. 39 y ss.

44 H.P. SCHNEIDER, Democracia y Constitución, CEC, 1991, pp. 49-50.

45 A. BALDASSARRE, Diritti della persona e valori costituzionale, Torino, 1997, pp. XVI-XVII. 
damento ético-cultural y jurídico de la democracia pluralista y connota la estructural apertura y el dinamismo de fondo.

La vía de las Cláusulas generales de validez nos ha llevado al campo de los valores y, ahora, nos reconducen al ámbito de los derechos fundamentales. Vamos a seguir, entonces, con el argumento inicial, esto es, con la integración de los derechos implícitos desde esta categoría dogmático-constitucional.

\section{B) La vía de los derechos transversales}

En esta vía debemos situar lo que la doctrina italiana ha calificado como "derechos transversales", a los que ya hemos hecho referencia.

Se trata de conectar varios derechos fundamentales, expresamente recogidos por el constituyente y, como origen de los mismos, los valores y bienes jurídicos que resultan complementarios. De esta forma, si no se acepta que únicamente los valores puedan fundamentar, de manera autónoma, "nuevos derechos", sí se podrá ver, en su relación pluridimensional, este derecho no expresamente recogido en el texto constitucional. Se trataría de derechos que inciden en el contenido de otros derechos, pero que resultan igualmente reconocibles a pesar de su ausencia formal.

Tanto esta vía, como la de las Cláusulas generales presentan el problema apuntado por Pace y por otros autores, y al que nos hemos referido brevemente, del peligro de una fuga a favor de opciones interpretativas individuales y, sobre todo, que este hecho implique, además, una limitación para los derechos expresamente previstos en la Constitución.

En cuanto a la limitación de otros derechos, sí es verdad que se va a producir, pero las limitaciones al respecto, vendrán marcadas por la propia Constitución y, aquí, el intérprete deberá ser riguroso al respecto. Como ya señaló el Tribunal Constitucional en fecha temprana (STC 2/82) "no existen derechos ilimitados. Todo derecho tiene sus límites que...en relación a los derechos fundamentales, establece la Constitución por sí misma en algunas ocasiones, mientras en otras el límite deriva de una manera mediata o indirecta de tal norma, en cuanto ha de justificarse por la necesidad de proteger o preservar no sólo otros derechos constitucionales, sino también otros bienes constitucionalmente protegidos". Además, en pronunciamientos posteriores, el Tribunal ha ido precisando el carácter y el fundamento de los límites, señalando que "...las limitaciones que se establezcan no pueden ser absolutas (STC 20/1990), ni obstruir el derecho fundamental más allá de lo razonable (STC 53/1986), pues la fuerza expansiva de todo derecho fundamental restringe el alcance de las normas limitadoras que actúan sobre él. De ahí la exigencia de que los límites a los derechos fundamentales hayan de ser interpretados con criterios restrictivos y en el sentido más favorable a la eficacia y a la esencia de tales derechos (SSTC 159/1986, 254/1988, 3/1997) ${ }^{46}$.

46 STC 301/2006. 
En el marco del constitucionalismo, como apunta Prieto Sanchis ${ }^{47}$, los derechos aparecen ya delimitados en el texto constitucional y, dentro de ese circulo delimitado, no cabe ninguna restricción; el legislador no puede inventar límites a los derechos. Ahora bien, sin querer adentrarnos en este tema tan complejo, sí ha de tenerse en cuenta que junto al límite, referido a la propia naturaleza de los derechos fundamentales, esto es, su significado jurídico, y junto al límite más relevante, desde la perspectiva del orden jurídico, que es el que deriva de la presencia de los derechos de los demás, existe otro límite, derivado de las necesidades sociales. De aquí que, efectivamente, se abra un campo con cierta amplitud para el intérprete quien deberá, en cada caso, respetar el marco fijado por el constituyente pero, la ampliación de derechos, aunque suponga, lógicamente restricción de otros, para el Tribunal Constitucional, será válida si es necesaria y proporcionada, o lo que es lo mismo, acorde con la Constitución ${ }^{48}$.

Sin duda el verdadero problema se plantea cuando se produce una colisión entre derechos. En este caso el intérprete debe de acudir a una ponderación entre los valores en conflicto para llegar a un equilibrio entre ambos. Díez Picazo apunta el riesgo que supone caer en el puro subjetivismo ya que conduce a decidir según las preferencias personales del intérprete. Para evitar este riesgo, este autor recurre a los planteamientos ya apuntados por Alexy en relación con la técnica de la ponderación. Muy resumidamente, dicha técnica comprende el análisis minucioso del caso concreto, tanto en sus aspectos fácticos como jurídicos, con el fin de evitar el sacrificio de un valor a costa del otro. Si esto no es posible, habría que determinar cuál de los dos valores es más digno de protección en el caso concreto, evitando así la interpretación subjetiva, y finalmente, puesto que uno de los valores no tiene por que quedar anulado en su totalidad, hay que acudir al principio de proporcionalidad que exige» entre otras cosas, que el valor o bien jurídico sacrificado lo sea únicamente en la medida necesaria para dar efectividad a aquél que goza de prioridad; y por tanto, a igual efectividad, debe preferirse siempre la solución menos gravosa ${ }^{49}$.

De la misma forma debe de ocurrir cuando se trate de interpretar los valores del ordenamiento. Siendo conscientes de que las disposiciones constitucionales recogidas de manera abstracta por el constituyente amplían el campo de decisión del Tribunal, éste no deberá prescindir de la debida atención a las disposiciones constitucionales que tales valores reciben y expre-

47 L. PRIETO SANCHIS, "La limitación de los derechos fundamentales y la norma de clausura del sistema de libertades", Derechos y Libertades, Revista del Instituto Bartolomé de las Casas, núm. 8, 2000, p. 430.

48 Cfr. STC 66/1995, de 8 de mayo. Sobre el complejo problema de la interpretación de los derechos fundamentales, vid R. ALEXY, Teoría de los derechos fundamentales, CEC, 2001 (segunda reimpresión), y "Epílogo a la Teoría de los derechos fundamentales", REDC, núm. 66, septiembre-diciembre 2002; C. BERNAL PULIDO, El principio de proporcionalidad y los derechos fundamentales, CEP y C, 2003, y "Tribunal Constitucional, legislador y principio de proporcinalidad", REDC, núm. 74, mayo-agosto 2005.

49 L.M. DÍEZ-PICAZO, Sistema de derechos fundamentales, op. cit. pp. 52-54. 
$\operatorname{san}^{50}$. Precisamente esta amplitud en el campo interpretativo que se le deja al Tribunal Constitucional, lleva a algunos autores a admitir su preferencia por el legislador para llevar a cabo esta tarea integradora. $\mathrm{E}$ incluso, hay quienes van más allá, y apuntan hacia la reforma constitucional como instrumento más adecuado frente a la interpretación extensiva.

Sobre este último extremo, para Ferreres Comella ${ }^{51}$ y, compartimos absolutamente su crítica, esta exigencia resulta excesiva teniendo en cuenta la rigidez de nuestro texto constitucional. Las Cláusulas más abstractas que figuran en una Constitución tan rígida - en materia de derechos- como la española, deben interpretarse como cláusulas de salvaguardia que el poder constituyente ha querido incluir a fin de mantener su obra a lo largo del tiempo sin necesidad de operar reformas explícitas del texto.

Una última objeción, apuntada hace ya tiempo por Hesse, es el peligro de que la ampliación de derechos, sobre todo a través de las Cláusulas generales, provoque una inflación de derechos que trivialice el significado de los mismos. No todos los derechos deben ser considerados derechos fundamentales y, en este sentido, no todos deben estar en el texto de la Constitución. Revenga Sanchez ${ }^{52}$, tras un análisis de esta cuestión en relación con la jurisprudencia Europea afirma que, por fortuna para una teoría de los derechos dotada de cierta coherencia, ha prevalecido la mesura; el reconocimiento de derechos nuevos por la justicia constitucional no se ha producido en Europa, sobre la base exclusiva de principios o valores generales de textura abierta, sino mediante el recurso a una interpretación evolutiva, apoyada en ellos, de los derechos con mención expresa en el texto de la Constitución.

Ejemplos de esta labor de "actualización" de derechos por parte del Tribunal Constitucional español los encontramos, principalmente, en relación con el derecho a la tutela judicial efectiva: el derecho al recurso en materia penal (STC 61/1983), el derecho a la ejecución de las resoluciones judiciales firmes (STC 125/1987) formarían parte del artículo 24.1 CE a los que se aplicaría, incluso, el "plus" de garantías del que difruta este precepto, el recurso de amparo en los términos del artículo $53.2 \mathrm{CE}$, así como la rigidez del artículo 168 CE. La apertura semántica del derecho a la tutela judicial permite incluir en su contenido tales posiciones jurídicas o derechos que el Tribunal Constitucional no ha hecho más que verificar ${ }^{33}$.

50 Cfr A. PACE, “Diritti Fondamentali al di lá della Costituzione?", Politica del Diritto, a. XXIV, núm. 1, 1993, pp. 5-7. 128-129.

51 V. FERRERES COMELLA, Justicia Constitucional y Democracia, CEP y C, Madrid, 1997, pp.

52 M. REVENGA SÁNCHEZ, "Sobre (viejos) modelos de Justicia constitucional y creación de (nuevos) derechos", ob. cit., pp 105-106.

53 En relación con esta función "integradora" y de concreción de los derechos fundamentales podemos citar la STC 254/1993 y la STC 292/2000 donde el Tribunal Constitucional reconoce implícito en el artículo 18.4 CE el derecho fundamental a la protección de datos en su conexión con derechos tales como el honor, la intimidad, la libertad así como la dignidad personal. Otros ejemplos de la tarea integradora llevada a cabo por el Tribunal pueden ser, entre otras, las SSTC 38/1981, 84/1989, 254/1993; 77/1995, 181/94. 


\section{C) Los Tratados y Convenios internacionales}

A través de estos instrumentos de carácter internacional se produce, dentro de los Estados firmantes, una especie de proceso de integración a un ámbito superior, en este caso, en materia de derechos fundamentales, que permite enriquecer las perspectivas nacionales a través, entre otros mecanismos, de la experiencia foránea.

En el ámbito de la Unión Europea resulta evidente, sobre todo por la existencia del Convenio de Roma de 1950, de la Carta de los derechos fundamentales de la Unión Europea, a pesar de su actual carácter político y, sobre todo, del Tribunal Europeo de Derechos Humanos. Esto permite un acercamiento en las formas de concebir los derechos fundamentales, en el tratamiento de los problemas que les afectan y, en definitiva, en buscar lo que Häberle denomina un ius comune constitucionale en Europa, prácticamente existente en materia de derechos fundamentales.

Con carácter general, el artículo 10.2 de la Constitución española es una clara prueba de la apertura del Estado al Derecho Internacional y, más concretamente, al Derecho Internacional de los derechos humanos ${ }^{54}$.

Sin embargo, el artículo 10.2 CE no permite la incorporación de nuevos derechos, en sentido estricto, al catálogo de derechos fundamentales recogidos en el Capítulo II del Título I CE. El Tribunal Constitucional en la STC 64/1991 así lo establecía expresamente al negar a los tratados y acuerdos internacionales la función de "...canon autónomo de validez de las normas y actos de los poderes públicos desde la perspectiva de los derechos fundamentales..... Ahora bien, esta afirmación no impide, para Rubio Llorente, dar claridad a los derechos fundamentales recogidos expresamente en la Constitución y, en su condición de intérprete supremo de la misma, "crear" derechos nuevos como parte de aquellos que la Constitución consagra ${ }^{55}$. Es decir, derechos implícitos que completan el contenido de los derechos fundamentales expresos y que, por tanto, ven reforzada su garantía y protección.

Partiendo de que el Capítulo II del Título I de la Constitución nos aproxima, en palabras de Saiz Arnáiz, "al estándar con el que opera el Tribunal de Luxemburgo y también, el Tribunal de Estrasburgo", resulta "difícil la hipótesis

54 En relación con esta función "integradora" y de concreción de los derechos fundamentales podemos citar la STC 254/1993 y la STC 292/2000 donde el Tribunal Constitucional reconoce implícito en el artículo 18.4 CE el derecho fundamental a la protección de datos en su conexión con derechos tales como el honor, la intimidad, la libertad así como la dignidad personal. Otros ejemplos de la tarea integradora llevada a cabo por el Tribunal pueden ser, entre otras, las SSTC 38/1981, 84/1989, 254/1993; 77/1995, 181/94.

El artículo 10.2 de la CE podría incluirse como un tipo de cláusula general de validez en la medida en que el reclamo a la normativa internacional haga posible una ampliación o incluso una implementación de los derechos recogidos en la Constitución. Vid el apartado A del epígrafe III.1 sobre las cláusulas generales de validez, p. 20.

55 F. RUBIO LLORENTE, “Los derechos fundamentales. Evolución, fuentes y titulares en España", Claves, núm. 75, 1997, p. 6. 
de la existencia de un derecho reconocido en algún Tratado firmado por España válidamente que no tenga su correspondiente constitucional... o no pueda vincularse a alguno de éstos, por lo que, en teoría, resulta poco imaginable el supuesto del derecho totalmente desvinculado del catálogo del Capítulo II del título I CE, ${ }^{56}$.

Pero, además y, como ya hemos apuntado, no sólo los Tratados y Convenios Internacionales válidamente celebrados por el Estado español juegan un papel destacado en la concreción de los derechos fundamentales "expresos", también las decisiones de los órganos internacionales de garantía como el Tribunal de Justicia de las Comunidades Europeas y de manera especial, el Tribunal Europeo de Derechos Humanos, contribuyen al enriquecimiento y actualización de la parte dogmática de nuestra Constitución.

El caso López Ostra c. España de 9 de diciembre de 1994 consideró los malos olores dentro del concepto de "molestias externas" como causa de vulneración del derecho a la intimidad. Años más tarde, el Tribunal de Estrasburgo en el caso Moreno Gómez c. España de 16 de noviembre de 2004 considera, también, la contaminación acústica como vulneración del derecho a la intimidad. El Tribunal Constitucional ha ido adaptando su jurisprudencia a la doctrina del Tribunal Europeo y, así, en la STC 119/2001, por ejemplo, se recoge esta nueva perspectiva en relación con el derecho a la integridad física y moral y, con otros derechos fundamentales relacionados como son la intimidad personal y familiar, y la inviolabilidad del domicilio ${ }^{57}$. Resulta evidente que la influencia de la doctrina del Tribunal de Estrasburgo ha tenido como gran efecto el incremento en el grado de protección de los derechos fundamentales reconocidos en la Constitución, de lo que se deduce que no podría ser utilizada para restringir el ámbito de los derechos fundamentales, tal y como el constituyente los recogió en la Norma Fundamental ${ }^{58}$.

Desde una perspectiva diferente, aunque también en materia de derechos fundamentales, debemos situar al Tribunal de Justicia de las Comunidades Europeas. Su activismo judicial en la tutela de los derechos fundamentales en el ámbito de la Comunidad viene motivado en buena medida, a juicio de Saiz Arnáiz, para contrarrestar la "sublevación de los Tribunales Constitucionales

56 A. SAIZ ARNÁIZ, La apertura constitucional al Derecho Internacional y Europeo de los derechos humanos. El artículo 10.2 de la Constitución española, CGPJ, 1999, p. 84.

57 En esta sentencia, el Tribunal Constitucional reconoce expresamente, ex artículo $10.2 \mathrm{CE}$, la doctrina del TEDH en su interpretación y tutela de los derechos fundamentales y así, utiliza la argumentación de este Tribunal cuando establece «...en determinados casos de especial gravedad, ciertos daños ambientales aun cuando no pongan en peligro la salud de las personas, pueden atentar contra su derecho al respeto de su vida privada y familiar, privándole del disfrute de su domicilio, en los términos del artículo 8.1 del Convenio", para incluir tanto los malos olores como los niveles de saturación acústica como motivos de vulneración del derecho a la intimidad. Lo mismo ocurrió en el caso Valenzuela Contreras c. España, sentencia de 30 de junio de 1998, que condenó al Estado español por permitir iterceptación de comunicaciones judicialmente autorizada pero sin cobertura legal. El TC se adaptó a esta doctrina y como ejemplos de esta adaptación podemos citar las SSTC 49/1999, 175/2000, 184/2003, etc.

58 Cfr. A SAIZ ARNÁIZ, ob. cit., p. 165. 
alemán e italiano ${ }^{59}$. En cualquier caso y, precisamente para salvar este problema, hay que resaltar el reconocimiento que, respecto de los derechos de los Estados miembros en los Tratados Europeos, precisamente con la finalidad de garantizar su vigencia. Sobre todo, es a partir del año 1992 y, posteriormente con la Carta de Niza cuando el Tribunal de Justicia ha ido ampliando el elenco de derechos fundamentales vigentes en el ordenamiento comunitario y ensanchando el ámbito de los actos sujetos a su jurisdicción ${ }^{60}$. Sin embargo, la interpretación que hace el Tribunal de Justicia de los derechos fundamentales no parte de la protección del individuo sino, como advierte Saiz Arnáiz, más bien de la tutela del ordenamiento jurídico comunitario, de sus objetivos. Esta jurisprudencia se proyecta, así, sobre el interior de los Estados miembros cuando aplican el Derecho Comunitario. No obstante, el Tribunal Constitucional mantiene su doctrina acerca de la función del artículo 10.2 CE, también en relación con los Tratados comunitarios ya que, tiene razón Aparicio ${ }^{61}$ cuando insiste en que, aunque in genere todos los Tratados formen parte del bloque de la constitucionalidad, por tanto del Derecho interno, no son Constitución y, por tanto, la fuente primaria de interpretación sigue siendo esta última.

En definitiva y, como hemos tratado de comprobar, el Derecho internacional vendría a completar al Derecho interno, tratando de crear un marco común en esta materia de claro carácter internacional. parece evidente lo que, razonadamente, apunta Häberle ${ }^{62}$ de que en la medida en que la teoría constitucional nacional y la jurisdicción constitucional se "europeícen", se enriquecerá el "corpus iuris" nacional, se pluralizarán las fuentes nacionales de Derecho y se abrirán el cánon interno hacia fuera.

ABSTRACT. This article attempts to reflect on the bended search to strike a balance between the constancy and the change of the fundamental rights. The Constitution is the starting point of the fundamental rights as a dogmatic category. Therefore it cannot be isolated from the reality if we want it to continue being an alive and effective norm. For this reason the Constitution must introduce this update of rights, which is essential and inevitable taking into account the social, cultural and economic transformations that affect the buman being constantly. The research of means and techniques to strike this said balance will lead us to the reality of the fundamental rights at the present time, like a dynamic category.

59 ibidem p. 173.

60 Cfr. F. RUBIO LlORENTE, "La Carta Europea de derechos", Claves, núm. 122, mayo 2002.

61 M. A. APARICIO, “La cláusula interpretativa del art. $10.2 \mathrm{CE}$, como cláusula de integración y apertura constitucional a los derechos fundamentales", en Jueces para la Democracia, núm. 6, 1989, p. 11.

62 P. HÄBERLE, El Estado Constitucional, op. cit., p. 128. 